\title{
Stabilities of calcium carbonate and calcium phosphate prenucleation clusters: insights from free energy perturbation calculations
}

\author{
JUlie AUfOrT ${ }^{* 1}$, PAOlO RAITERI ${ }^{1}$, NATAlyA A. \\ GARCIA $^{1}$, RAFFAELLA DEMICHELIS ${ }^{1}$, JULIAN D. GALE ${ }^{1}$ \\ ${ }^{1}$ Curtin Institute for Computation, The Institute for \\ Geoscience Research (TIGeR), and School of Molecular \\ and Life Sciences, Curtin University, PO Box U1987, \\ Perth, WA 6845, Australia. (julie.aufort@curtin.edu.au)
}

Calcium carbonate and calcium phosphate are ubiquitous minerals, found not only in geological settings, but also in living organisms as the main inorganic component of seashells, pearls and eggshells (carbonates) and of vertebrate bones and teeth (phosphates). Despite their biomedical, ecological and economic relevance, the pathways by which these minerals nucleate from solution remain under debate. Recently, the observation of stable prenucleation clusters for $\mathrm{CaCO}_{3}$ [1] has raised the question as to whether such processes could occur in other biominerals and lead to a renewed interest in Posner's cluster $\mathrm{Ca}_{9}\left(\mathrm{PO}_{4}\right)_{6}$ [2], and in other possible calcium phosphate clusters such as $\left[\mathrm{Ca}\left(\mathrm{HPO}_{4}\right)_{3}\right]^{4-}$ [3]. However, while there is growing evidence for the presence of stable clusters in the early stages of calcium carbonate and calcium phosphate nucleation, their composition and structure remain difficult to probe with many experimental techniques, due to their short lifetime and very small size of a few nm at most.

Computer simulations offer a valuable complement to the available experimental information. Classical molecular dynamics, based on forcefields accurately calibrated against experimental thermodynamic data, can provide quantitative information such as free energies and equilibrium constants. In this contribution, we examine a series of calcium carbonate [4] and calcium phosphate [2,5] clusters of interest, such as $\left[\mathrm{CaCO}_{3}\right]_{7},\left[\mathrm{Ca}\left(\mathrm{HPO}_{4}\right)_{2}\right]^{2-},\left[\mathrm{Ca}_{2}\left(\mathrm{HPO}_{4}\right)_{4}\right]^{4-}$ and $\mathrm{Ca}_{9}\left(\mathrm{PO}_{4}\right)_{6}$, and use classical molecular dynamics with Free Energy methods to determine their formation and solvation free energies. The relative stabilities of these clusters and their implication for calcium carbonate and calcium phosphate nucleation pathways will be discussed.

[1] Gebauer, Voelkel, Coelfen, Science 2008, 322, 1819-1822. [2] Betts, Posner, Mater. Res. Bull. 1974, 9, 353-360. [3] Habraken, et al. Nat. Commun. 2013, 4, 1507. [4] Sun et al. Angew. Chem. Int. Ed. 2016, 55, 1-5. [5] Garcia, et al. Cryst. Growth Des. 2019, 19, 11, 6422-6430 